\title{
Sınır Kişilik Bozukluğu Özellikleri ile İlişkili Değişkenler: Üniversite Öğrencileri Üzerinden İnceleme
}

\author{
Ümit MORSÜNBÜL*
}

Öz

Kişilik bozuklukları içerisinde üzerine en fazla çalışılan ve incelenen bozukluk sınır kişilik bozukluğudur (SKB). Bu çalışmanın temel amacı kimlik boyutlarının, depresyonun, anksiyetenin ve narsisizm özelliklerinin SKB özelliklerini ne yönde yordadığını incelemektir. Çalışmada ilişkisel tarama modeli kullanılmıştır. Çalışmanın araştırma grubu toplam 264 (141 erkek, 123 kadın) kişiden oluşmaktadır. Katılımcıların yaş aralığı 18-24, yaş ortalaması ise 20.46 \$1.05 yıldır. Katılımcıların SKB özelliklerini belirlemek amacıyla Borderline Kişilik Envanteri, kimlik boyutlarını belirlemek amacıyla Utrecht Kimlik Bağlanma Ölçeği, narsisizm özelliklerini belirlemek amaciyla Narsisizm Ölçeği, depresyon puanlarını belirlemek amacıyla Beck Depresyon Envanteri ve son olarak da anksiyete düzeylerini belirlemek amacıyla Beck Anksiyete Envanteri kullanılmıştır. Regresyon analizi sonuçlarına göre cinsiyet, bağlanma yapma, narsisizm, depresyon ve anksiyete SKB'yi anlamlı olarak yordamaktadır. SKB'nin en güçlü yordayıcısı depresyonken en zayıf yordayıcısı ise cinsiyettir. Bu çalışmanın sonuçları cinsiyetin, kimlik boyutlarının, depresyonun, anksiyetenin ve narsisizm özelliklerinin SKB'da önemli değișkenler olduğunu göstermiştir. Bu sonuç ruh sağlığı uzmanlarının bu bozukluğu gösteren bireylerle ilgilenirken bu değișkenleri göz önünde bulundurmaları gerektiğini ortaya koymaktadır.

Anahtar Kelimeler: Sınır Kişilik Bozukluğu, Kimlik, Depresyon, Anksiyete, Narsisizm

\section{Variables Associated with Borderline Personality Disorder Characteristics: An Investigation through University Students}

\section{Abstract}

The most studied and investigated disorder is Borderline Personality Disorder (BPD) among personality disorders. The purpose of this study is to investigate how identity dimensions, depression, anxiety and narcissism characteristics predict BPD characteristics. Correlational descriptive model was used in the present study. The research group consisted of 264 (141 male, 123 female) participants and their ages are between 18-24 years old (mean=20.46 \pm 1.05$)$. Borderline Personality Inventory, Utrecht-

\author{
Özgün Araştırma Makalesi (Original Research Article) \\ Geliş/Received: 17.12.2019 \\ Kabul/Accepted: 23.02.2020 \\ DOI: https://dx.doi.org/10.17336/igusbd.657954 \\ * Doç. Dr., Aksaray Üniversitesi, Eğitim Fakültesi, Rehberlik ve Psikolojik Danışmanlık ABD, Aksaray, \\ Türkiye, E-posta: morsunbulumit@gmail.com ORCID http://orcid.org/0000-0002-0750-5015
}


Management of Identity Commitments Scale, Narcissistic Personality Inventory, Beck Depression Inventory, and Beck Anxiety Inventory were used in order to collect data. According to regression analysis results gender, commitment making, narcissism, depression and anxiety significantly predicted BPD. Depression is the best predictor of BPD, while gender is the weakest predictors of BPD. The results of this study showed that gender, identity dimensions, depression, anxiety and narcissism are important variables in BPD. This result suggests that mental health professionals should consider these variables when dealing with individuals who exhibit this disorder.

Keywords: Borderline personality disorder, Identity, Depression, Anxiety, Narcissism

\section{Giriş}

Kișilik bireye özgü olan, onu diğerlerinden ayıran ve büyük ölçüde kararlılık gösteren özellikler bütünü olarak tanımlanabilir (Öztürk, 2002). Kişilik bozukluğu belirtileri gösteren bireyler, benlikleriyle, kimlikleriyle ve hayatlarının diğer alanlarında özellikle de kişilerarası ilişkilerde uzun zaman süren sıkıntılar yaşamaktadırlar. Kișilik bozuklukları içerisinde klinik ortamda çok sık rastlandığı, tedavisinin zor olması ve intiharla ilişkili olması nedeniyle sınırda kişilik bozukluğu diğer kişilik bozukluklarına göre daha fazla ilgi çekmiştir (Kring vd., 2015). Ruhsal Bozuklukların Tanısal ve İstatistiksel Elkitabında (Diagnostic and Statistical Manual of Mental Disorders, DSM 5) sınırda kişilik bozukluğu (SKB) için istikrarsız benlik/kimlik duygusu, kronik boşluk hissi, tekrarlayan öfke nöbetleri ve intihar düşünceleri/girişimleri, tepkisellik, terk edilmekten korkma ve bu durumun olmaması için sürekli çaba içerisinde olma kriterlerinin tanılama için belirtildiği görülmektedir. SKB belirtileri gösteren bireylerin özellikle kimlik duygusunda sorunlar yaşadıkları, sıklıkla depresyon ve anksiyete belirtileri gösterdikleri ve narsistik özelliklere sahip oldukları (özellikle psikodinamik bakış açısından) belirtilmektedir (Öztürk, 2002; Kring vd., 2015; Çalışır, 2008). Bu nedenden dolayı bu çalışmada SKB'nin yordayıcıları olarak bu değişkenlere odaklanılmıștır.

Kişilik gibi kimlikte tanımlanması zor bir kavram olarak karşımıza çıkmaktadır. En basit haliyle kimlik ben kimim? sorusuna verilen cevap olarak tanımlanmaktadır. Erikson (1968) kimliği aynılık ve süreklilik duygusu olarak tanımlamaktadır. Sürekli bir kimlik duygusuna sahip bireyler sağlıklı ruhsal özellikler ortaya koymakta ve yaşamıyla ilgili sorumlulukları daha güçlü bir şekilde üstlenmektedirler (Erikson, 1968; Morsünbül ve Çok, 2013; Schwartz vd., 2011). Kimlik gelişimi ile ilgili literatüre bakıldığında Kuramsal olarak Erikson'nun (1968) ve Marcia'nın (1980) çalışmalarına dayanılarak araştırmaların yapıldığı görülmektedir. Son yıllarda ise Marcia'nın (1980) kimlik statüleri modelinin genişletilmiş hali olan ve özellikle kimlik süreçlerine odaklanan modellerin ön plana çıktığı görülmektedir. Bu modellerden biri de Crocetti ve diğerleri (2008) tarafından önerilen Üç Boyutlu Kimlik Gelişimi Modelidir. Bu modelde kimlik gelişiminde üç temel süreç tanımlanmıştır. Bunlardan ilki olan bağlanma yapma kimlik alanıyla ilgili konularda karara varmak ve kararın kalıcı hale getirilmesidir. İkincisi bireyin bağlanmaları hakkında araştırmalar yapması olan derinlemesine keşiftir. Son süreç ise bireyin var olan bağlanmaları ona yetersiz geldiğinde farklı kimlik alternatifleri için tekrar araștırma sürecine girdiği bağlanmanın yeniden gözden geçirilmesidir (Crocetti vd., 2008). Bağlanma yapma ve derinlemesine keșif olumlu ruh sağlığı özellikleri ile olumlu olarak ilişkiliyken bağlanmanın yeniden gözden geçirilmesi ise olumsuz olarak ilişkilidir (Crocetti vd., 2008; Morsünbül vd., 2016).

Çalışmada depresyon ve anksiyete SKB'nin yordayıcısı olarak ele alınan diğer iki değişkendir. Duygudurum ve anksiyete bozuklukları SKB belirtileri gösteren bireylerde 
eştanı olarak en fazla tanılanan bozukluklar olarak ortaya çıkmaktadır. Hatta bazı araştırmacılar SKB belirtileri gösteren bireylerin kişilik bozukluğu ile tanımlanması yerine bipolar tanısıyla tanımlanarak bireylere daha etkili tedavi uygulanabileceğini belirtmektedirler (Perugi vd., 2003; Çalışır, 2008).

Çalışmada SKB'nin yordayıcısı olarak ele alınan son değișken ise narsisizmdir. Narsisizm kişinin bașka kişilere karşı ben merkezli bir șekilde davranmasını göstermektedir. Bu kişilerin aşırı derecede kendilerinden hoşnutlukları vardır ve kendi ihtiyaç ve arzularını her zaman ilk sırada görürler bu nedenle başkalarına karşı empati gösterme konusunda da oldukça büyük sorunlar yaşarlar (Santrock, 2014). Narsistik özellikler sergileyen bireyler eleştiriye karşı aşırı hasastırlar ve diğerleri onlara hayranlık duymadığında aşırı öfkelenebilirler (Kring vd., 2015). Psikodinamik bakış açısından SKB ve narsistik özelikler aynı spektrumun farklı uçları olarak ele alınmaktadır ve birbiriyle kesișen noktaları vardır (Anlı ve Bahadır, 2007). Narsisizm üzerine ayrıntılı açıklamalarda bulunan Kohut iki tür narsisizm tanımlamıştır. Olumlu bir gelişimsel yapı olarak sağlıklı narsisizm ve normal gelişim sürecinde bir takılma olarak patolojik narsisizmdir. Kohut'un tersine Kernberg ise narsisizmi tamamiyla olumsuz bir durum olarak değerlendirmiștir (Anlı ve Bahadır, 2007). Narsistik kişilik bozukluğu belirtileri gösteren bireyler belirgin biçimde kendini üstte görme, sadece kendisiyle ilgilenme eğilimindedirler (Kring vd., 2015).

Buraya kadar aktarılan literatürün ışığında bu çalışmanın temel amacı kimlik boyutlarının, depresyonun, anksiyetenin ve narsisizm özelliklerinin SKB özelliklerini ne yönde yordadığını belirlemektir. Bu amaç doğrultusunda çalışma yapılırken değişkenlerle ilgili puanlar tanılayıcı kategoriler olarak değil, özellik belirlemek amacıyla kullanılmıştır. Örneğin katılımcıların SKB puanları bireylerin bu bozukluğa sahip/sahip değil gibi tanılayıcı bir amaç olarak kullanılmamıştır. $\mathrm{Bu}$ nedenle bu çalışmadan elde edilen puanlarla herhangi bir tanılayıcı kategori iddiasında bulunulmamaktadır.

\section{Yöntem}

\section{Araştırma Modeli}

Bu çalışmada mevcut durumu inceleyen ilişkisel tarama modeli kullanılmıştır.

\section{Katılımcılar}

Çalışmanın araştırma grubu Aksaray Üniversitesi Eğitim Fakültesinde eğitim gören 141 (\%53.4) erkek ve 123 (\% 46.6) kadın olmak üzere toplam 264 kişiden oluşmaktadır. Araștırma grubunun yaș aralığı 18-24, yaș ortalaması ise $20.46 \pm 1.05$ yıldır.

\section{Veri Toplama Araçları}

Kişisel Bilgi Formu: Katılımcıların demografik özelliklerini belirlemek amacıyla kişisel bilgi formundan yararlanılmıștır.

Borderline Kişilik Envanteri (BKE): Katılımcıların sınır kişilik özelliklerini incelemek için Leichsenring (1999) tarafından geliştirilen ve Aydemir ve diğerleri (2006) tarafından Türkçe'ye adapte edilen BKE'den yararlanılmıştır. Envanter toplam 50 maddeden oluşmaktadır. Envanterde katılımcı tarafından uygun bulunup işaretlenen her ifadeye 1 , seçilmeyen ifadelere ise 0 puan verilmektedir. Ölçeğin Türkçeye adapte çalışmasında Cronbach alfa iç tutarlılık katsayısı 0.92 olarak hesaplanmıştır. Bu çalışmada Cronbach alfa iç tutarlılık katsayısı 0.81 olarak hesaplanmıştır.

Utrecht Kimlik Bağlanma Ölçeği (UKBÖ): Kimlik altboyutlarını incelemek için Crocetti ve arkadaşları (2008) tarafından geliştirilen ve Morsünbül ve diğerleri (2014) 
tarafından Türkçe'ye adapte edilen UKBÖ’den yararlanılmıştır. UKBÖ 1-5 arası puanlanan Likert tipi bir ölçme aracıdır. Ölçek toplam 26 madde ve üç boyuttan oluşmaktadır. Ölçeğin Türkçeye adapte çalışmasında Cronbach alfa iç tutarlılık katsayıları 0.79-0.87 arasında hesaplanmıştır. Bu çalışmada Cronbach alfa iç tutarlılık katsayıları 0.75-0.85 arasında olduğu saptanmıştır.

Narsisizm Ölçeği (NÖ): Narsisizm özelliklerini incelemek için Ames ve diğerleri (2006) tarafından geliştirilen ve Güngör ve Selçuk (2015) tarafından Türkçe’ye uyarlanan NÖ kullanılmıştır. Ölçek 16 maddeden oluşmaktadır ve katılımcılardan her bir madde için iki şıktan birini işaretlenmesi beklenmektedir. Ölçeğin Türkçe adaptasyonunda Cronbach alfa iç tutarlılık katsayısı 0.74 olarak belirlenmiştir. Bu çalışmada Cronbach alfa iç tutarlılık katsayısı 0.84 olarak hesaplanmıştır.

Beck Depresyon Envanteri (BDE): Katılımciların depresyon puanlarını incelemek için Beck (1984) tarafından geliştirilen ve Hisli (1988, 1989) tarafından Türkçe adaptasyonu yapılan BDE kullanılmıştır. Ölçek 21 maddeden oluşmaktadır ve her bir madde 0'dan 3'e kadar depresyonun ciddiyetine göre sıralanmıştır. Ölçme aracının Türkçe adaptasyonunda Cronbach alfa iç tutarlılık katsayısı 0.80 olarak belirlenmiştir. Bu çalışmada Cronbach alfa iç tutarlılık katsayısı 0.77 olarak hesaplanmıştır.

Beck Anksiyete Envanteri (BDE): Katılımcıların anksiyete düzeylerini belirlemek amacıyla Beck ve diğerleri (1988) tarafından geliştirilen ve Ulusoy ve diğerleri (1998) tarafından Türkçe adaptasyonu yapılan BDE kullanılmıştır. Ölçek 21 maddeden oluşan, 03 arası puanlanan likert tipi bir ölçektir. Ölçeğin Türkçe adaptasyonunda Cronbach alfa iç tutarlılık katsayısı 0.93 olarak belirlenmiştir. Bu çalışmada Cronbach alfa iç tutarlılık katsayısı 0.90 olarak hesaplanmıștır.

\section{İşlem}

Ölçme araçlarının uygulanması için ilgili birimlerden izinler alınmıştır. Uygulamalar sınıf ortamında gruplar halinde yapılmıștır. Çalışmanın amacı ve ölçme araçlarıyla ilgili katılımcılara bilgi verilmiş ve onam formları alınmıștır. Uygulamalar ortalama olarak 35-45 dakika sürmüştür.

\section{Verilerin Analizi}

Verilerin inceleneceği analizler için uygunluğunu belirlemek amacıyla normallik analizi kullanılmıştır. Sonuçlar çarpıklık ve basıklık değerlerinin +1.5 ile -1.5 arasında olduğunu göstermiştir. Çarpıklık katsayıları 0.11 ile 1.14, basıklık katsayısı -0.08 ile 1.33 arasındadır. Bağımsız değişkenler arasında çoklu bağlantı probleminin olup olmadığına bakmak için değișkenler arasındaki ikili korelasyonlara bakılmıștır. Değişkenler arasında .80 ve üzeri korelasyon saptanmamıştır. Değişkenler arasında çoklu bağlantı probleminin belirlenmesi için ayrıca VIF (1.12 ile 1.66 arasında değişmekte) ve Tolerans ( 0.59 ile 0.89 arasında değişmekte) değerlerine bakılmış ve çoklu bağlantı probleminin olmadığı saptanmıștır. Değişkenler birbirleriyle olan ilişkilerini belirlemek amacıyla Korelasyon analizi, bağımsız değişkenlerin SKB'yi yordayıp yordamadıklarını incelemek için de çoklu regresyon analizi kullanılmıştır.

\section{Bulgular}

Bu bölümde ilk olarak çalışmadaki değişkenlere ait betimsel istatistik sonuçları aktarılmıştır. Daha sonra regresyon analizine ilişkin sonuçlar aktarılmıştır. 


\section{Değişkenler Arasındaki İlişskiler}

Değișkenlere ilișkin ortalamalar, standart sapmalar ve aralarındaki ilişkiler Tablo 1 'de verilmiștir.

Tablo 1. Değişkenlere ilişkin Ortalamalar, Standart Sapmalar ve Aralarındaki İlişkiler

\begin{tabular}{|l|l|l|l|l|l|l|l|l|l|}
\hline Değișken & Ort. & SS & 1 & 2 & 3 & 4 & 5 & 6 & 7 \\
\hline $\begin{array}{l}\text { 1.Sinır kişilik } \\
\text { bozukluğu }\end{array}$ & 1.22 & .11 & & & & & & & \\
\hline $\begin{array}{l}\text { 2.Bağlanma } \\
\text { yapma }\end{array}$ & 3.61 & .62 & $-.27^{* *}$ & & & & & & \\
\hline $\begin{array}{l}\text { 3.Derinlemesine } \\
\text { keșif }\end{array}$ & 2.90 & .51 & -.07 & $.51^{* *}$ & & & & & \\
\hline $\begin{array}{l}\text { 4. Bağlanmanın } \\
\text { yeniden gözden }\end{array}$ & 2.15 & .65 & $.24^{* *}$ & $-.21^{* *}$ & .00 & & & & \\
\hline 5.Narsisizm & 4.46 & 3.84 & $.24^{* *}$ & .03 & $-.13^{*}$ & $.13^{*}$ & & & \\
\hline 6.Depresyon & .57 & .31 & $.56^{* *}$ & $-.23^{* *}$ & .08 & $.20^{* *}$ & -.12 & & \\
\hline 7.Anksiyete & .77 & .47 & $.46^{* *}$ & .00 & $.13^{*}$ & $.19^{* *}$ & .11 & $.47^{* *}$ & \\
\hline
\end{tabular}

${ }^{*} \mathrm{p}<.05,{ }^{* *} \mathrm{p}<.01$

Tablo 1'deki sonuçlara bakıldığında SKB ile en yüksek düzeyde anlamlı olarak ilişkide olan değișken depresyon iken $(\mathrm{r}=.56, \mathrm{p}<.01)$, en düşük düzeyde anlamlı olarak ilişkide olan değişkenler ise bağlanmanın yeniden gözden geçirilmesi $(r=.24, p<.01)$ ve narsisizmdir $(\mathrm{r}=.24, \mathrm{p}<.01)$.

\section{Regresyon Analizi Sonuçları}

Tablo 2. Regresyon Analizi Sonuçları

\begin{tabular}{|c|c|c|c|c|c|c|}
\hline Model & $\begin{array}{c}\text { Standartlaştırılmamış } \\
\text { Katsayılar }\end{array}$ & & $\begin{array}{c}\text { Standartlaştırılmış } \\
\text { Katsayılar }\end{array}$ & & & \\
\hline & B & $\begin{array}{c}\text { Standart } \\
\text { Hata }\end{array}$ & Beta & $\mathbf{T}$ & $\mathbf{R}$ & $\mathbf{R}^{2}$ \\
\hline Sabit & 60.39 & 2.41 & & 25.01 & & \\
\hline Cinsiyet & -1.28 & .58 & -.10 & $-2.19^{*}$ & & \\
\hline $\begin{array}{l}\text { Bağlanma } \\
\text { Yapma }\end{array}$ & -.17 & .05 & -.18 & $3.13^{* *}$ & .69 & .48 \\
\hline $\begin{array}{l}\text { Derinlemesine } \\
\text { Keșif }\end{array}$ & -.05 & .06 & -.04 & -.81 & & \\
\hline $\begin{array}{l}\text { Bağlanmanın } \\
\text { Yeniden Gözden } \\
\text { Geçirilmesi }\end{array}$ & .07 & .07 & .05 & 1.03 & & \\
\hline Narsisizm & .42 & .07 & .27 & $5.84^{* *}$ & & \\
\hline Depresyon & .38 & .05 & .42 & $7.67^{* *}$ & & \\
\hline Anksiyete & .12 & .03 & .20 & $3.86^{* *}$ & & \\
\hline
\end{tabular}

${ }^{*} p<.05,{ }^{* *} p<.01$, Cinsiyet: $0=$ Kadın, $1=$ Erkek

Bağımsız değişkenlerin SKB'yi ne yönde yordadığını belirlemek amacıyla yapılan regresyon analizi sonuçları Tablo 2'de verilmiștir. Sonuçlara bakıldığında bağımsız değişkenlerin ( $\left.\mathrm{R}=.69, \mathrm{R}^{2}=.48, \mathrm{~F}=34.39, \mathrm{p}<.01\right)$ SKB'yi anlamlı düzeyde açlkladığ görülmektedir. Bağımsız değişkenlere ilişkin $t$ testi sonuçlarına göre cinsiyet $(\beta=-.10$, $\mathrm{p}<.05)$, bağlanma yapma $(\beta=-.18, \mathrm{p}<.01)$, narsisizm $(\beta=.27, \mathrm{p}<.01)$, depresyon $(\beta=.42$, $\mathrm{p}<.01)$ ve anksiyete $(\beta=.20, \mathrm{p}<.01)$ SKB'yi anlamlı olarak yordamaktadır. 


\section{Tartışma ve Sonuç}

$\mathrm{Bu}$ çalışmanın temel amacı cinsiyetin, kimlik boyutlarının, depresyonun, anksiyetenin ve narsisizm özelliklerinin SKB özelliklerini ne yönde yordadığını belirlemektir. Çalışmanın sonuçları bağımsız değişkenlerin SKB'yi anlamlı olarak yordadığını göstermiştir. Cinsiyet açısından sonuçlar SKB kriterlerinin kadınlar arasında daha yaygın olduğunu göstermiştir. Daha önce yapılan çalışmaların (Akhtar, Byrne ve Doghramhi, 1986; Widiger ve Trull, 2007) sonuçlarına bakıldığında bazı çalışmalarda bu çalışmanın sonuçları ile tutarlı olarak SKB'nin kadınlarda daha yaygın olduğunu gösterirken, farklı çalışmalarda (Barzega, Maina, Venturello ve Bogetto, 2001; Carter, Joyce, Mulder, Sullivan ve Luty, 1999; Henry ve Cohen, 1983) ise erkekler arasinda SKB'nin daha yaygın olduğu gösterilmiştir. SKB belirtileri gösteren erkekler eş tanı olarak daha çok madde kullanımı bozukluğu, şizotipal, narsisistik ve antisosyal kişilik bozukluğu ile tanılandıkları belirtilmektedir. Kadınlarda ise eş tanı olarak daha çok fiziksel ve cinsel istismara maruz kalma sonucunda yașanan travma sonrası stres bozukluğuyla ya da yeme bozuklukları ile tanılandıkları belirtilmektedir (Johnson vd., 2003). Bazı araștırmacılar kişilik bozukluklarında belirli kısmında (antisosyal ve narsistik) erkeklere yönelik belirli bir kısmında (SKB, histriyonik, bağımlı) ise kadınlara yönelik tanılanma eğiliminin olduğunu belirtmektedirler. Bu bozuklukların kadınlara ya da erkeklere özel olmadığı bunun daha çok toplumsal cinsiyet önyargıları ile ilgili olabileceği belirtilmektedir (Kring vd., 2015).

Kimlik boyutları açısından bakıldığında regresyon sonuçları bağlanma yapmanın SKB'yi negatif yönde yordadığını göstermiștir. Bağlanma yapma bireyin kimliğiyle ilgili sürekli ve tutarlı bir kimlik duygusuna sahip olduğunu göstermektedir (Crocetti, 2008). SKB'nin temel kriterlerinden biri olan istikrarsız kimlik duygusu kimlik alanıyla ilgili herhangi bir güçlü ve tutarlı bağlanmanın olmadığını göstermektedir. Regresyon analizi sonuçlarında anlamlı çıkmamasına karşın korelasyon analizi sonuçlarına bakıldığında bağlanmanın yeniden gözden geçirilmesi SKB ile pozitif yönde ilişkilidir. Bu kimlik boyutunda bireyler sahip oldukları bağlanmaları onlara tatmin edici gelmediği için sıklıkla kimlik alanıyla ilgili tekrar tekrar araştırma yapmaktadırlar. Bu araştırmalar kimlikle ilgili bağlanma ile sonuçlanmadığı için bireyler sürekli bir keşfe saplanırlar. Başka deyişle kimlikle ilgili ruminasyon yaşarlar. Bu durumda büyük ölçüde SKB'deki boşluk hissi yaşama belirtisine neden olmaktadır (Boagerts vd., 2018; Kaufman vd., 2014; Westen, Betan ve Defife, 2011).

Çalışmanın sonuçları narsisizmin depresyondan sonra SKB'nin en güçlü yordayıcısı olduğunu göstermiştir. Psikodinamik bakış açısı SKB'nin ve narsistik özeliklerin çoğu zaman birbiriyle örtüştüğ̈̈nü ve benzer etiyolojilere sahip olduklarını belirtmektedir (Anlı ve Bahadır, 2007). Bu bakış açısından SKB ve narsizm madalyonun iki yüzü gibidir. Bir tarafi (SKB) kendiliğe ilişkin yetersiz bir libidinal yatırımı gösterirken, diğer tarafı (narsisizm) ise yüzeyde kendiliğe dair büyüklenmeci patolojik olarak aşırı bir libidinal yatırımı göstermektedir (Anlı ve Bahadır, 2007). Her iki tarafta da bireyler kendilikleriyle ilgili problemler yaşamaktadırlar. Kernberg ve Yeomans (2013) örtüşmelerine karşın iki bozukluk arasında ayrımlar yapılabileceğini belirtmektedirler. İlk farklılık narsist özellikler gösteren bireylerin herhangi bir bağımlılık ilişkisini kabul etmedeki isteksizlikleridir. İkinci farklılık narsisistik özellikler gösteren bireyler așırı suçluluk ve aşağılık duyguları ve orantısız üstünlük ve grandiyöz duyguları arasında gidip gelirler. Üçüncü olarak da narsisitik özellikler gösteren bireyler yoğun bir sosyal ağ ilişkileri içerisinde olmalarına karşın sosyal olarak izole bir durumu deneyimlerler. Bu nedenle ilişkilerini sürdürme konusunda sıkıntı yaşarlar ya da çoğu zaman ilişkide oldukları kişileri kaybederler. 
Çalıșmanın sonuçları depresyonun ve anksiyetenin SKB'nin anlamlı yordayıcıları olduğunu göstermiştir. SKB'de duygusal düzensizlik sıklıkla görülmekte ve majör depresyon eş tanı olarak konulabilmektedir (McGlashan vd., 2000; Paris, 2011). Geçmişte SKB depresyonun atipik formu olarak görülmüștür. Akiskal'a (2004) göre SKB sınır kişilik bozukluğu bipolar bozuklukla büyük benzerlikler göstermektedir. Akiskal'in bu açıklamasına karşı çıkan araştırmacılar SKB ile bipolar bozukluk arasında belirgin farklılıklar olduğunu belirtmiştir. Bipolar bozukluk zaman içersinde sabit kalırken ya da daha da kötüleşirken çoğu SKB hastası zaman içerisinde düzelmekte ve özellikle orta yaşlarda bozukluğun kriterlerini karşılamamaya başlamaktadırlar. Bunun yanında lityum gibi bipolar bozukluklarda işlevsel olan ilaçların SKB hastalarında çok işlevsel olmadığı belirtilmektedir (Paris, 2011).

Çalışma önemli sonuçlar ortaya koymasına karşın bazı sınırlılıklar içermektedir. Çalışmanın en önemli sınırlılığı verilerin klinik olmayan gruptan toplanmasıdır. Bundan sonraki çalışmalarda kliniksel olarak tanılanmış gruplarla çalışılması daha derin açıklamalar sağlayabilir. Çalıșmanın ikinci sınırlılığı verilerin üniversite eğitimi alan beliren yetişkinlerden toplanmasıdır. Gelecek çalıșmalarda farklı yaşam evrelerinde olan ve öğrenci olamayan gruplarla çalıșllabilir.

$\mathrm{Bu}$ çalışmanın sonuçları cinsiyetin, kimlik boyutlarının, depresyonun, anksiyetenin ve narsisizm özelliklerinin SKB'da önemli değișkenler olduğunu göstermiştir. $\mathrm{Bu}$ sonuç ruh sağlığı uzmanlarının bu bozukluğu gösteren bireylerle ilgilenirken bu değişkenleri göz önünde bulundurmaları gerektiğini ortaya koymaktadır.

\section{KAYNAKÇA}

AKHTAR, S., BYRNE J. \& DOGHRAMHI, K (1986). The demographic profile of borderline personality disorder. Journal of Clinical Psychiatry 47:196-198.

AKISKAL, H.S. (1999). The evolving bipolar spectrum: prototypes I, II, III, and IV. Psychiatric Clinics of North America 22:517-534.

AMERIKKAN PSIKIYYATRİ BİRLİĞİ (2013) Ruhsal Bozuklukların Tanısal ve Sayımsal El Kitabı, Beşinci Baskı (DSM-5) (Çev. ed.: E Köroğlu) Hekimler Yayın Birliği, Ankara.

AMES, D.R., ROSE, P. \& ANDERSON, C.P. (2006). The NPI-16 as a short measure of narcissism. Journal of Research in Personality, 40:440-50.

ANLI, İ. \& BAHADIR, G. (2007). Kendilik Psikolojisine Göre Narsisistik Ve Sınır Kişilik Bozukluğu. İstanbul Üniversitesi Psikoloji Çalışmaları Dergisi 27:56-63.

AYDEMIR, Ö., DEMET, M.M., DANACI, A.E. ve diğ. (2006) Borderline kişilik envanterinin Türkçe'ye uyarlanması, güvenirliği ve geçerliliği. Psychiatry in Türkiye 8:610.

BARZEGA, G., MAINA, G., VENTURELLO, S. \& BOGETTO, F. (2001). Gender-related distribution of personality disorders in a sample of patients with panic disorder. European Psychologist, 16:173-179.

BECK, A.T. (1984). Internal consistencies of the original and revised Beck Deprresion Inventory. Journal of Clinical Psychology, 40:1365-67.

BECK, A.T., EPSTEIN, N., BROWN, G.\& STEER, R.A. (1988). An inventory for measuring clinical anxiety: Psychometric properties. Journal of Counsulting and Clinical Psychology, 56: 893-97.

BOAGAERTS, A., CLAES, L., VERSHUEREN, M. ve diğ. (2018). The Dutch SelfConcept and Identity Measure (SCIM): Factor structure and assocations with identity dimensions and psychopathology. Personality and Individual Differences, 123:56-64. 
CARTER, J.D., JOYCE, P.R., MULDER, R.T., SULLIVAN, P.F. \& LUTY, S.E. (1999). Gender differences in the frequency of personality disorders in depressed outpatients. Journal of Personality Disorders, 13:67-74.

CROCETTI, E., RUBINI, M., LUYCKX, K. \& MEEUS, W. (2008). Identity formation in early and middle adolescents from various ethnic groups: From three dimensions to five statuses. Journal of Youth and Adolescence, 37:983-96.

ÇALIŞIR, M. (2008). Sınırda kişilik bozukluğu aslında bir bipolar spektrum bozukluğu mudur?. Klinik Psikiyatri 11:143-52.

ERIKSON, E. (1968). Identity, Youth and Crisis. New York: Norton.

GÜNGÖR, N.D. \& Selçuk, F.Ü. (2015). Narsisistik Kişilik Envanteri (NKE-16): Türkçe Uyarlaması. Atılım Üniversitesi Sosyal Bilimler Araştırma ve Eğitim Laboratuvarı (SAEL), Yayınlanmamış Tartışma Metni, sael.atilim.edu.tr.

HENRY, K.A., COHEN, C.I. (1983). The role of labeling processes in diagnosing borderline personality disorder. American Journal of Psychiatry, 140:1527-29.

HISLİ, N. (1989). Beck Depresyon Envanterinin üniversite öğrencileri için geçerliği ve güvenirliği. Psikoloji Dergisi 7: 3-13.

KAUFMAN, E. A., CUNDIFF, J.M. \& CROWELL, S.E. (2015). The development, factor structure, and validation of the Self-concept and Identity Measure (SCIM): A selfreport assessment of clinical identity disturbance. Journal of Psychopathology and Behavioral Assessment, 37:122-133.

KERNBERG, O.F. \& YEOMANS, F.E. (2013). Borderline personality disorder, bipolar disorder, depression, attention deficit/hyperactivity disorder, and narcissistic personality disorder: Practical differential diagnosis. Bulletin of Menninger Clinic, 77:122.

KRING, A.M., JOHNSON, S.L., DAVISON, G. \& NEALE, J. (2015). Anormal Psikolojisi (Çev. ed.: M. Şahin). Nobel Akademik Yayıncılık, Ankara.

LEICSENRING, F. (1999). Development and first results of the Borderline Personality Inventory: A self-report instrument for assessing borderline personality organization. Journal of Personality Assessment, 73: 45-63.

JOHNSON, D.M., SHEA M.T., YEN, S. ve diğ. (2003). Gender differences in borderline personality disorder: Findings from the collaborative longitudinal personality disorders study. Comprehensive Psychology, 44:284-92.

MARCIA, J.E. (1980). Identity in adolescence (Ed. J Adelson), Handbook of Adolescent Psychology. New York, Wiley, s.159-187.

MCGLASHAN, T.H., GRILO, C.M. \& SKODOL, A.E. (2000). The collaborative longitudinal personality disorders study: baseline axis I/II and II/III diagnostic cooccurrence. Acta Psychatrica Scandinavica, 102:256-64.

MORSÜNBÜL, Ü. \& ÇOK, F. (2013). Kimlik gelişiminde yeni bir boyut:

Seçeneklerin saplantılı araştırılması. Türk Psikolojik Danışma ve Rehberlik Dergisi 5:232-44.

MORSÜNBÜL, Ü., CROCETTI, E., ÇOK, F., MEEUS, W. (2014). The Utrecht Management of Identity Commitment Scale (U-MICS): Gender and age measurement invariance and convergent validity of the Turkish version. J Adoles 37:799-805.

MORSÜNBÜL, Ü., CROCETTI, E., ÇOK, F. \& MEEUS, W. (2016). Identity Formation in Turkish Youth: A Person Centered Approach. J Adoles 47:145-55.

ÖZTÜRK, O. (2002). Ruh sağlığı ve Bozuklukları. Nobel Tıp Kitapevleri, Ankara.

PARIS, J. (2011). Differential diagnosis of bipolar and borderline personality disorders. Neuropsychiatry 1:251-57.

PERUGI, G., AKISKAL, H. S., LATTANZI, L. ve diğ. (1998). The high prevelane of 'soft' bipolar (II) features in atypical depression. Comprehensive Psychiatry, 39: 63-71. 
SANTROCK, J.W. (2014). Ergenlik (Çev. Ed.: DM Siyez). Nobel Akademik Yayıncılık, Ankara.

SCHWARTZ, S. J., BEYERS, W., LUYCKX, K. Ve diğ. (2011). Examining the light and dark sides of emerging adults' identity: A study of identity status differences in positive and negative psychosocial functioning. Journal of Youth Adolescence, 40:839-59.

ULUSOY, M., SSAHIN, N. \& ERKMEN, H. (1998). Turkish Version of the Beck Anxiety Inventory: Psychometric Properties. Journal of Cognitive Psychotherapy, 12:163-172.

WESTEN, D., BETAN, E. \& DEFIFE, J.A. (2011) Identity disturbance in adolescence: Associations with borderline personality disorder. Dev Psychopath 23:305-313.

WIDIGER, T.A. \& TRULL, T.J. (2007). Plate tectonics in the classification of personality disorder: Shifting to a dimensional model. American Psychologist 62:71-83.

\section{Summary}

Personality is crucial variable for human adaptation and effects individuals' relationships with others. Individuals with personality disorders experience longterm problems with their selves, identities and other areas of their lives. One of them that the most investigated is Borderline Personality Disorder (BPD). According to Diagnostic and Statistical Manual of Mental Disorders 5 borderline personality disorder (BPD) is defined as sense of unstable self/identity, chronic emptiness, recurrent anger attacks and suicidal thougts/attempts, reactivity, and fear of abandonment.

It's stated that individuals with BPD especially experience problems in sense of identity, frequently show symptoms of depression and anxiety and have narcissistic features. Thus, study focused on these variables as predictors of BPD. The first one is identity formation that is difficult to define like personality. Several identity formation models have been proposed in recent years. A Three-dimensional identity model that focuses on three basic process in identity development was used in the present study. This model includes three dimensions (commitment, in-depth-exploration and reconsideration of commitment). The other two variables that investigated as predictor of BPD are depression and anxiety. Mood and anxiety disorders are the most comorbid disorders in individuals with BPD. The last variable that examined as predictor of BPD is narcissism. Narcissism reflects individual's self-centered behavior towards others. From the Psychodynamic viewpoint narcissism and $B P D$ are considered as different ends of the same spectrum. In light of previous literature, the aim of this study is to determine how identity dimensions, depression, anxiety and narcissism characteristics predict BPD.

The research group consisted of 264 (141 male, 123 female) university students and their ages are between 18-24 years old (mean=20.46士1.05). Borderline Personality Inventory, Utrecht-Management of Identity Commitments Scale, Narcissistic Personality Inventory, Beck Depression Inventory and Beck Anxiety Inventory were used in order to collect data.

Regression analysis indicated that the independent variables to account for $48 \%$ of the variance in BPD. The findings showed that gender, commitment, narcissism, depression and anxiety significantly predicted BPD. According to regression analysis depression is the best predictor of $B P D$, while gender is the weakest predictor of $B P D$.

This result suggests that mental health professionals should consider these variables when dealing with individuals who exhibit this disorder. Although the study shows significant results, it contains some limitations. The most important limitation of the study 
Ümit Morsünbül, “Sınır Kişilik Bozukluğu Özellikleri ile İlișkili Değișkenler: Üniversite Öğrencileri Üzerinden İnceleme”, İstanbul Gelişim Üniversitesi Sosyal Bilimler Dergisi, 7 (2), Ekim 2020, ss. 394-403.

is the collection of data from the non-clinical group. Working with clinically diagnosed groups in later studies may provide deeper explanations. 